\title{
GT2012-69681
}

\section{SIMULATION OF 2-WAY FLUID STRUCTURE INTERACTION IN A 3D MODEL COMBUSTOR}

\author{
Mina Shahi* \\ University of Twente \\ Department of Thermal \\ Engineering (THW), \\ School of Engineering (CTW), \\ Enschede,The Netherlands \\ m.shahi@ctw.utwente.nl
}

\author{
Jim.B.W. Kok \\ University of Twente \\ Department of Thermal \\ Engineering (THW), \\ School of Engineering (CTW), \\ Enschede,The Netherlands \\ J.B.W.Kok@ctw.utwente.nl
}

\author{
P.R. Alemela \\ Combustion Engineer \\ Engineering Department \\ Ansaldothomassen BV, \\ Rheden, The Netherlands \\ reddy.alemela@ansaldothomassen.nl
}

\section{ABSTRACT}

The liner of a gas turbine combustor is a very flexible structure that is exposed to the pressure oscillations that occur in the combustor. These pressure oscillations can be of very high amplitude due to thermoacoustic instability, when the fluctuations of the rate of heat release and the acoustic pressure waves amplify each other. The liner structure is a dynamic mechanical system that vibrates at its eigenfrequencies and at the frequencies by which it is forced by the pressure oscillations to which it is exposed. On the other hand the liner vibrations force a displacement of the flue gas near the wall in the combustor. The displacement is very small but this acts like a distributed acoustic source which is proportional to the liner wall acceleration. Hence liner and combustor are a coupled elasto-acoustic system. When this is exposed to a limit cycle oscillation the liner may fail due to fatigue.

In this paper the method and the results will be presented of the partitioned simulation of the coupled acousto-elastic system composed of the liner and the flue gas domain in the combustor. The partitioned simulation uses separate solvers for the flow domain and the structural domain, that operate in a coupled way. In this work 2-way fluid structure interaction is studied for the case of a model combustor for the operating conditions $40-60 \mathrm{~kW}$ with equivalence ratio of 0.625 . This is done in the framework of the LIMOUSINE project. Computational fluid dynamics analysis is performed to obtain the thermal loading of the combustor liner and finite element analysis renders the temperature, stress distribution and deformation in the liner. The software used is ANSYS workbench V13.0 software, in which the information (pressure and displacement) is also exchanged between fluid and structural domain transiently.

KEYWORDS: Fluid structure interaction, pressure oscillation, 3D combustor, thermo-acoustic instability

$\begin{array}{ll}\text { NOMENCLATURE } \\ \mathrm{E} & \text { Young's modulus } \\ \mathrm{T} & \text { Temperature } \\ \rho & \text { Density } \\ \nu & \text { Poisson's ratio } \\ \lambda & \text { Air excess ratio } \\ \varphi & \text { Equivalence ratio }\end{array}$

\section{INTRODUCTION}

Due to their reliable performance and wide stability characteristics, gas turbine engines with diffusion-flame combustors have been used extensively in propulsion and power generation applications. But unfortunately this kind of combustor produces unacceptable levels of nitrogen oxides or NOx [1]. So new concepts of combustion technology were introduced by means of lean premixed combustion, to avoid the formation of high temperature stoichiometric regions. this method leads to lower flame temperatures and consequently lower NOx emissions. However the main problem of lean premixed combustion of natural gas is its sensitivity to thermoacoustic instability. These combustors can exhibit significant flow and pressure oscillations. These oscillations may reach such amplitudes that they cause flame extinction, structural vibration, flame flashback and ultimately failure of 
the system [2,3]. Several coupled mechanisms are known to promote such interactions, for example, flame-acoustic wave interactions, flame vortex interactions, thermal-structure interactions, fluid-structure interactions, all of them may be present in a system individually or simultaneously [4-7].

Due to the high temperature of the flue gas in the combustion chamber, the liner of a gas turbine combustor has to be well cooled and therefore be thin, so there is a strong interaction with a feed back loop possible between the aerodynamics-combustion-structure. The structure is the most limiting element in this chain of events when it comes to the formation of a Limit Cycle Oscillation (LCO). So the aim of this paper is to explore the mechanism of fluid-structure interaction on the LIMOUSINE setup which leads to LCO. Numerical simulation is done by using ANSYS workbench V13.0 which is fairly easy to use compared to previous work done by Pozarlik [8], which uses additional interface software (MFX) for the coupling of the fluid and the structural domains. Pozarlik et al [9] compared the one way and two way interactions in a generic gas turbine combustion chamber, obtained results showed big differences between one and twoway interaction.

Similar calculations also were made by Alemela et al [10] for 2-way FSI simulation using ANSYS workbench v12.1, however in this work only a slice of $2 \mathrm{~mm}$ wide is considered for simulation which removes all the 3D flow patterns. In addition in their model the structural side did not include the end walls of the duct which would have added additional stiffness and have reduced the amplitude of wall displacement.

Huls et al.[11] reported measurements and calculation carried out on the DESIRE set up (a test rig at the university of Twente). They calculated the excitation pressures on the structure by using large eddy simulation (LES), then these pressures are used as loads in a the finite element model in order to measure the wall vibrations. In their approach there is only one-way coupling with the structure, and indeed no information from the structural domain is fed back in the LES.

\section{THERMO-ACOUSTIC INSTABILITY}

Thermo-acoustic instability is a phenomenon where pressure and heat release interact in a confined domain. The relation between a flame and the acoustic field was interpreted by Lord Rayleigh [12]. The Rayleigh criterion which recognizes the difference between damped or amplified interaction between pressure and heat release is often used to investigate and predict combustion instabilities. It states that if pressure and heat release fluctuations are in phase, the instabilities are enhanced, whereas the instabilities are damped when the pressure oscillations and heat release are out of phase. This criterion is expressed as following Equation:

$$
\iiint_{\Omega} p^{\prime} q^{\prime} d \Omega>0
$$

where $p^{\prime}$ and $q^{\prime}$ are pressure and heat release fluctuations, respectively, integrated over one cycle of the oscillation and $\Omega$ is the flow domain. Note that the integrals are also spatial, which means that both effects, destabilizing and stabilizing, can occur in different locations of the combustor and at different times, so the stability of the combustor will be decided by the net mechanical energy added to the combustor domain. Indeed when the acoustic energy losses match the energy gain a stationary oscillatory behaviour is obtained which is referred to as the limit cycle oscillation (LCO).

\section{COMBUSTOR SETUP DESCRIPTION}

The experiment, which is modeled here, is performed on a test rig which is shown in fig.1. It is located at the University of Twente and 4 other laboratories, within the framework of the European LIMOUSINE project. The setup is designed to study limit cycles due to thermo-acoustic instability. The combustion chamber consists of two rectangular ducts with different widths. The upstream duct is made of $25 \times 150 \mathrm{~mm}^{2}$ cross section and is $275 \mathrm{~mm}$ long, whereas the downstream duct has a $50 \times 150 \mathrm{~mm}^{2}$ cross sectional area to compensate the volume expansion due to combustion. In the transition between the ducts a wedge is mounted that stabilizes the flame. In this configuration which is the third design version of the combustor (V3), the total length of the combustor is $1050 \mathrm{~mm}$.

This configuration behaves like a variation of a Rijke tube [13] . It deviates from the standard Rijke tube because it is closed at the bottom end and open to the atmosphere at the downstream end. Air as the oxidizer is injected at the upstream end. Fuel used here is methane at room temperature and is injected from the side surfaces of the wedge through 62 holes.

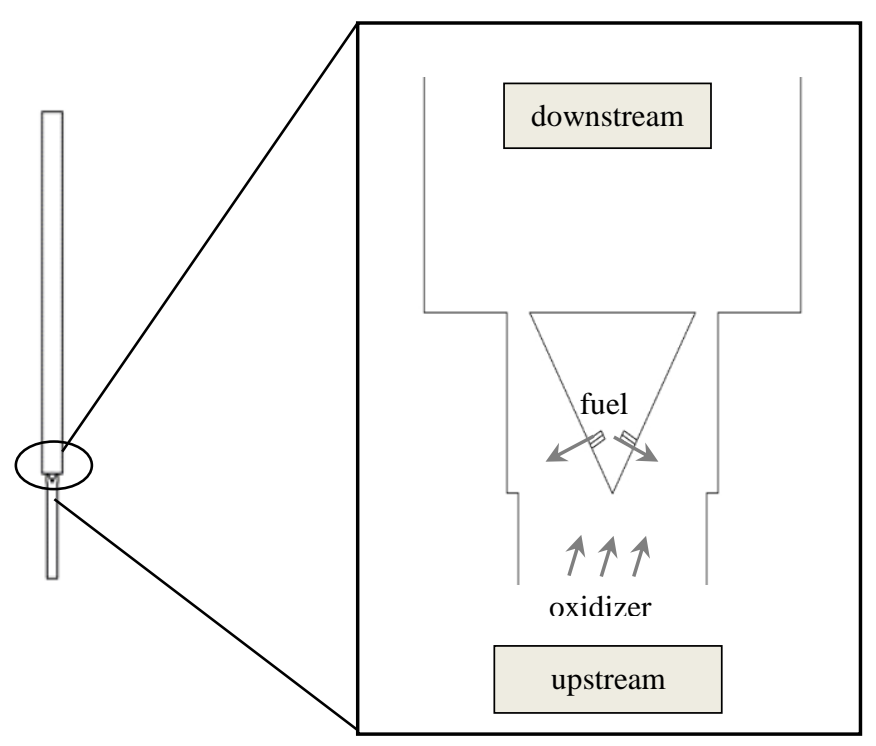

(a)

(b)

Fig1. (a) full combustor geometry (b) an enlarged view around the wedge 


\section{CFD NUMERICAL SIMULATION}

In the partitioned approach, separate and independent techniques with the appropriate interface boundary conditions are used for the fluid and solid domains.

In order to reduce the computational effort numerical calculations of the reacting flow inside the combustion chamber are done only for the half part of the geometry, which comprises half of the wedge and is $25 \mathrm{~mm}$ wide. The SAS-SST model available in the CFX code is used for the turbulence modeling [14], and the Burning Velocity Model (BVM) for the combustion [15]. A time constant average static pressure is imposed on the outlet. Symmetry boundary conditions are prescribed to the side wall while the other walls are adiabatic and have a no-slip condition. Details about the boundary conditions imposed on the fuel and air inlets are summarized in table 1.

The numerical scheme uses a high resolution advection scheme for spatial and second order backward Euler discretization for time accuracy. URANS simulations are carried out with a time step of 0.0001. At the monitor points the data is stored of the URANS simulations at every time step giving a sampling frequency of $10000 \mathrm{HZ}$, hence the maximum frequency observed is $5000 \mathrm{HZ}$. However data up to $1000 \mathrm{HZ}$ was presented in figures 7-10. A total calculation time of $0.25 \mathrm{~s}$ and residual target value of 1e-4 has been achieved.

Since the resolution of the grid has significant effects on the accuracy of results, several different meshes with various element size and distribution were tested for steady case and finally a total number of 1197787 unstructured tetrahedral elements is used for the mesh. The mesh is refined in the combustion zone and around the fuel inlets (see fig.2). The flow parameters are set consistent with the experimental conditions depicted in table 2. To obtain pressure fluctuations inside the combustion chamber and the displacement of the walls several locations along the length of the combustor and also along the length of walls are monitored which are shown in figs. $3 \& 4$.

Table 1: more details about inlet boundary conditions

\begin{tabular}{|c|c|c|c|c|c|}
\hline & B.c & $\begin{array}{c}\text { T } \\
(\mathrm{k})\end{array}$ & $\begin{array}{c}\text { Mixture } \\
\text { fraction }\end{array}$ & $\begin{array}{c}\text { Reaction } \\
\text { progress }\end{array}$ & $\begin{array}{c}\text { Turbulence } \\
\text { (intensity) }\end{array}$ \\
\hline $\begin{array}{c}\text { Air } \\
\text { Inlet }\end{array}$ & $\begin{array}{c}\text { Mass } \\
\text { flow } \\
\text { rate }\end{array}$ & 293 & 0 & 0 & $5 \%$ \\
\hline $\begin{array}{c}\text { Fuel } \\
\text { inlet }\end{array}$ & $\begin{array}{c}\text { Normal } \\
\text { speed }\end{array}$ & 293 & 1 & 0 & $5 \%$ \\
\hline
\end{tabular}

Table 2: operating condition

\begin{tabular}{|c|c|c|c|}
\hline $\begin{array}{c}\text { Power } \\
(\mathrm{kW})\end{array}$ & $\begin{array}{c}\text { Air } \\
\text { factor }\end{array}$ & $\begin{array}{c}\text { Fuel mass } \\
\text { flow rate } \\
{[\mathrm{kg} / \mathrm{s}]}\end{array}$ & $\begin{array}{c}\text { Air mass flow } \\
\text { rate }[\mathrm{kg} / \mathrm{s}]\end{array}$ \\
\hline 40 & 1.6 & $8 \mathrm{e}-04$ & 0.021888 \\
\hline 60 & 1.6 & 0.0012 & 0.032832 \\
\hline
\end{tabular}

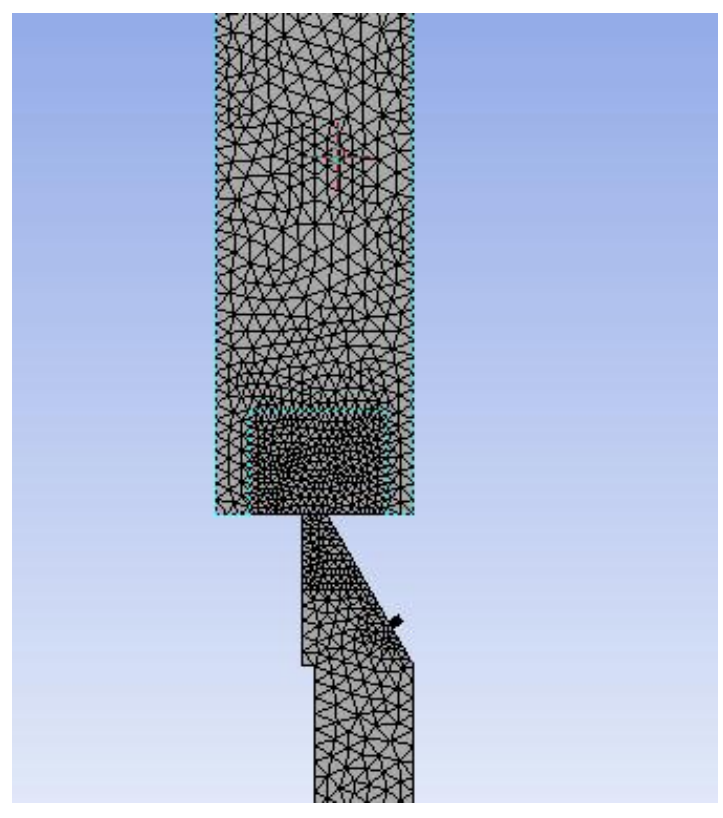

Fig 2. mesh details of the limousine combustor

\section{CSD NUMERICAL COMPUTATION}

Because most of the dynamic coupling between the hot fluid and structure occurs in the region downstream of the wedge, in this simulation only the structure downstream of the wedge is considered which is shown in fig. 3. The wall is simplified to three plates forming half of a cube without quartz glass windows or holes for thermocouples and pressure transducer. A uniform wall temperature equal to $400^{\circ} \mathrm{C}$ and material properties according to this temperature are used for the analysis. The liner of the test rig was modeled as an elastic material (Shell 63 [16] with $1 \mathrm{~mm}$ thickness) with the properties representing hot steel at $400^{\circ} \mathrm{C}$ which are shown in table 3. The total number of 2450 shell elements equally distributed is used for this simulation. Mechanical loads, i.e. pressure and shear are transferred from the CFD domain to structural part at every time step. The clamped-clamped boundary condition is implemented at two ends, while the rest of the surface is allowed to deform freely depending on the dynamic pressure loads. The total calculation real time is $0.25 \mathrm{~s}$.

\section{TWO-WAY FSI COUPLING}

During the two way interaction analysis the CFX and ANSYS softwares exchange information dynamically every time step, as shown in figure 5. Compare to the one way interaction it is possible to observe the impact of the wall vibration on the pressure distribution inside the combustion chamber as well as the effect of the new pressure on the wall vibration. During the 2-way fluid structure interaction (FSI) numerical simulation using ANSYS V13.0 workbench the data from a steady state solution (CFX fluid flow module A) is fed into the static structural analysis (ANSYS module B) and then to the transient structural (ANSYS module D) and fluid flow (CFX fluid flow module E). A 2-way coupling between the 
fluid and structure is obtained by linking the modules D and E and then transferring surface loads/displacements across physics interface. In this way the quantities from the fluid computations are applied directly on the geometry and then the new deformed structure is updated in the fluid simulation. The total mesh displacement is transferred across the interface by preserving the profile between the two fields, while the total force will be transferred using a conservative formulation.

This procedure will be repeated until a converged solution is obtained, then the calculation will continue in the next time step. This procedure has three levels of iterations which is shown in figure 6.

\section{MESH DEFORMATION}

In order to account the arbitrary mesh movement, it is necessary to modify the governing equation to include the motion of the mesh. So the transient convection term must be modified when the control volumes deform in time. These modifications follow from the application of the Leibnitz Rule:

$\frac{d}{d t} \int_{V(t)} \varphi d V=\int_{V} \frac{\partial \varphi}{\partial t} d V+\int_{s} \varphi W_{j} d n_{j}$

where $W_{j}$ is the velocity of the control volume boundary.

So the differential conservation equations are integrated over a given control volume. At this juncture, the Leibnitz Rule is applied, and the integral conservation equations become:

$$
\frac{d}{d t} \int_{V(t)} \rho d V+\int_{s} \rho\left(U_{j}-W_{j}\right) d n_{j}=0
$$

$\frac{d}{d t} \int_{V(t)} \rho U_{j} d V+\int_{s} \rho\left(U_{j}-W_{j}\right) U_{j} d n_{j}=-\int_{s} P d n_{j}+$

$$
\int_{S} \mu_{e f f}\left(\frac{\partial U_{i}}{\partial x_{j}}+\frac{\partial U_{j}}{\partial x_{i}}\right) d n_{j}+\int_{V} S_{U_{i}} d V
$$

$V$ is the volume, $S$ is the surface, and $\mu_{e f f}$ is the effective viscosity including the dynamic viscosity and the turbulent viscosity.

$$
\begin{aligned}
\frac{d}{d t} \int_{V(t)} \rho \varphi d V+\int_{S} \rho\left(U_{j}-W_{j}\right) \varphi d n_{j} \\
=\int_{S} \Gamma_{e f f}\left(\frac{\partial \varphi}{\partial x_{j}}\right) d n_{j}+\int_{V} S_{\varphi} d V
\end{aligned}
$$

The transient term accounts for the rate of change of storage in the deforming control volume, and the advection term accounts for the net advective transport across the control volume's moving boundaries .

The mesh deformation is available only for fluid domain which enables the specification of the motion of nodes on boundary. The motion of all remaining nodes (i.e. the regions of nodes with the same degrees of freedom) is determined with the Displacement Diffusion Model. With this model the displacement of domain boundaries or subdomains are diffused to other mesh points by solving the following equation:

$\nabla .\left(\Gamma_{\text {dis }} \nabla \delta\right)=0$

In this equation, $\delta$ is the displacement relative to previous mesh locations and $\Gamma_{\text {dis }}$ is the mesh stiffness, which determines the degree to which regions of nodes move together. It is worth noting that the displacement diffusion model for mesh motion is designed to preserve the relative mesh distribution of the initial mesh.

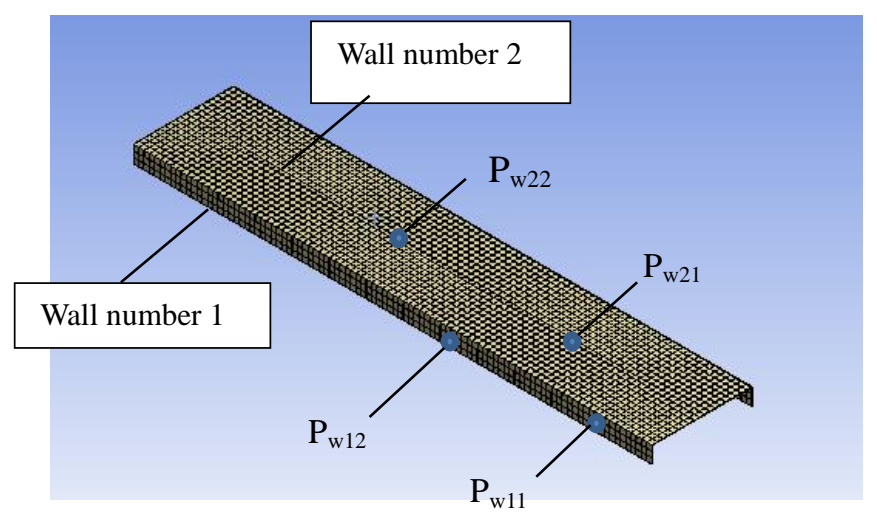

Fig 3. The FE model of the thin liner with pressure sensors on walls

Table 3: Material Properties and configuration

\begin{tabular}{|c|c|c|c|c|}
\hline & $\begin{array}{c}\text { Young's } \\
\text { modulus }\left(\mathrm{N} / \mathrm{m}^{2}\right)\end{array}$ & $\begin{array}{c}\text { Poisson's } \\
\text { ratio }\end{array}$ & $\begin{array}{c}\text { Density } \\
{\left[\mathrm{kg} / \mathrm{m}^{3}\right]}\end{array}$ & $\begin{array}{c}\text { Thickness } \\
(\mathrm{mm})\end{array}$ \\
\hline Hot steel & $1.76 \mathrm{E} 11$ & 0.3 & 7715 & 1 \\
\hline
\end{tabular}

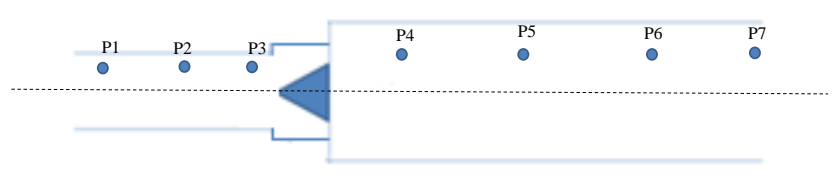

Fig 4. Pressure sensors on CFD domain upstream and downstream of the wedge

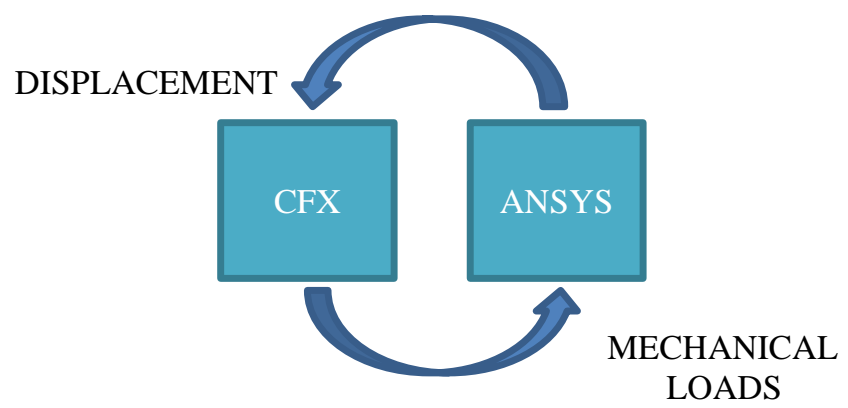

Fig 5. 2-way interaction 


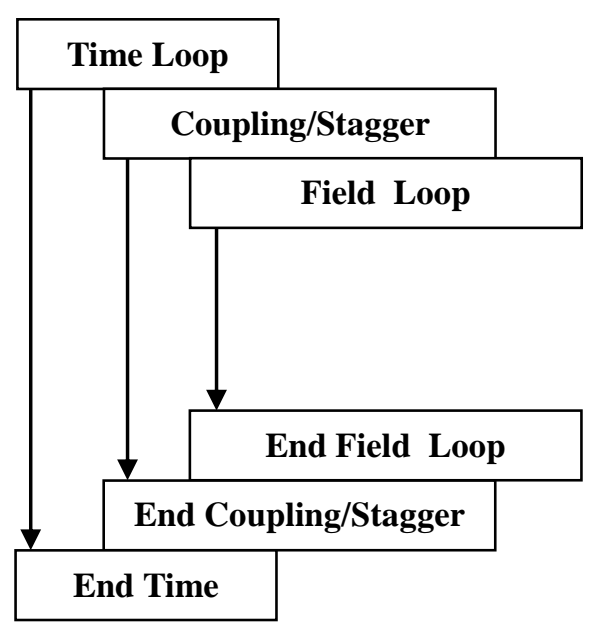

Fig 6. Process scheme of 2-way FSI simulation

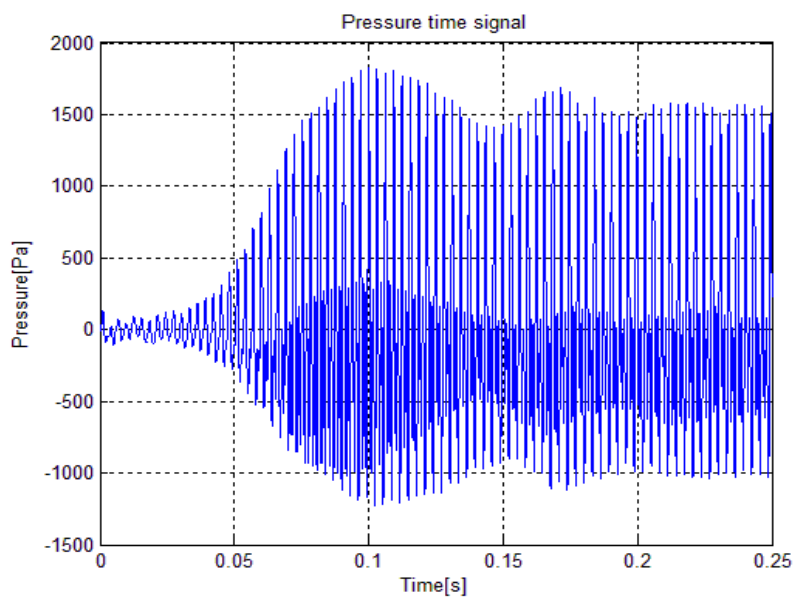

(a)

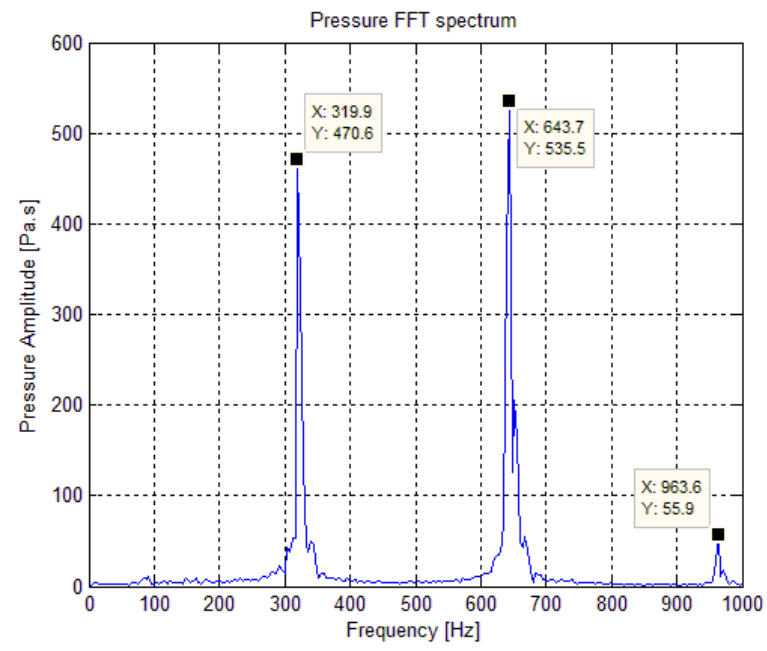

(b)

Fig7. Calculated self-exited pressure oscillation as a function of (a) time (b) frequency at the location $500 \mathrm{~mm}$ above the wedge for the case of $60 \mathrm{~kW}$ and $\varphi=0.625$.

\section{RESULTS/ACOUSTIC BEHAVIOR}

In order to compute the resonant frequencies as observed in the experiment, we analytically modelled the combustor acoustics. The (assumed one dimensional) acoustics of the combustor are calculated by solving the linear one dimensional wave equation. If we assume the current set up configuration to have closed-open boundary conditions at the ends, then the equation of calculating the fundamental frequency can be expressed as :

$\mathrm{f}_{\mathrm{n}}=(2 \mathrm{n}-1) \mathrm{c} / 4 \mathrm{~L}$

Where $\mathrm{c}$ is the speed of sound which is corresponding to the adiabatic flame temperature in the combustor (in this case is equal to $1800 \mathrm{~K}$ ), and $\mathrm{L}=0.78 \mathrm{~m}$ is the downstream length of the combustor. According to this equation the first Eigen mode of the combustor is around $292 \mathrm{~Hz}$.

Figure 7 shows the calculated evolution of pressure over time within the burner at the location $500 \mathrm{~mm}$ above the wedge. Due to the rapid growth of the oscillation amplitude characterising the phase of oscillation, the system will soon reach to a $1500 \mathrm{~Pa}$ amplitude, hence it is predicted that a stationary limit cycle oscillation (LCO) is reached. On the second part of the image (fig7-b), we see the pressure spectrum showing the first three distinct peaks.

According to the calculation the first and third amplitude peaks are observed at frequencies presenting the first and the third quarter wave modes. Another observed peak, where the main instability is located, is exactly the double of the first eigenfrequency of the combustor and might be due to the frequency doubling of the first eigenfrequency. This is a nonlinear effect. The pressure spectrum clearly shows a strong oscillation at the frequency of $\sim 320 \mathrm{~Hz}$ and $\sim 643 \mathrm{HZ}$.

Table 4 and 5 show the frequency and amplitude of pressure oscillations at 3 observed peaks in auto spectrum plots obtained at different locations according to fig. 4 , respectively upstream and downstream of the wedge for the case of 60KW thermal power and $\varphi=0.625$. Data recorded for the first peak shows that the frequency of $\sim 320 \mathrm{HZ}$ corresponds to the $1 / 4$ wave mode of the combustor and pressure amplitude is decreasing along the combustor, which confirms the openclosed acoustic boundary condition, showing that the captured wave is a standing wave. However you can see a big jump in pressure amplitude passing from upstream to downstream, which is due to the change of the cross section and the presence of the wedge.

Table 4: Predicted eigenfrequencies and pressure amplitude at different locations Upstream of the wedge for the case of $60 \mathrm{KW}$

\begin{tabular}{|c|c|c|c|c|c|c|}
\hline & \multicolumn{2}{|c|}{ First peak } & \multicolumn{2}{|c|}{ Second peak } & \multicolumn{2}{|c|}{ Third peak } \\
\hline & $\begin{array}{l}\text { Freq } \\
\text { [HZ] }\end{array}$ & $\begin{array}{l}\text { Amp } \\
{[\mathrm{Pa} . \mathrm{s}]}\end{array}$ & $\begin{array}{l}\text { Freq } \\
{[\mathrm{HZ}]}\end{array}$ & $\begin{array}{l}\text { Amp } \\
{[\text { Pa.s] }}\end{array}$ & $\begin{array}{l}\text { Freq } \\
\text { [HZ] }\end{array}$ & $\begin{array}{l}\text { Amp } \\
{[\mathrm{Pa} . \mathrm{s}]}\end{array}$ \\
\hline P1 & \multirow{3}{*}{319.9} & 1327 & \multirow{3}{*}{643.7} & 413.6 & \multirow{3}{*}{963.6} & 42.56 \\
\hline $\mathrm{P} 2$ & & 924.6 & & 93.48 & & 71.28 \\
\hline $\mathrm{P} 3$ & & 305.8 & & 482.7 & & 17.58 \\
\hline
\end{tabular}




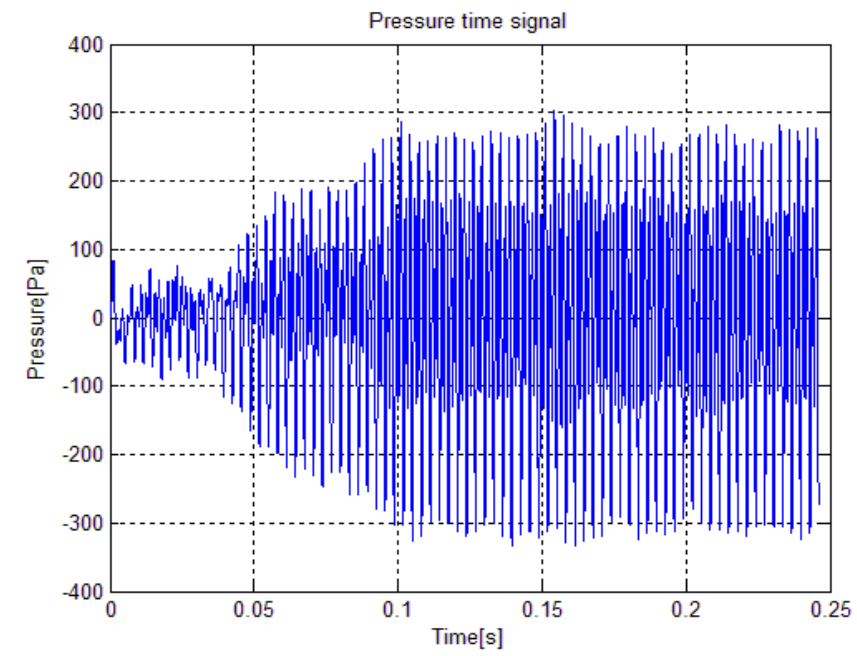

(a)

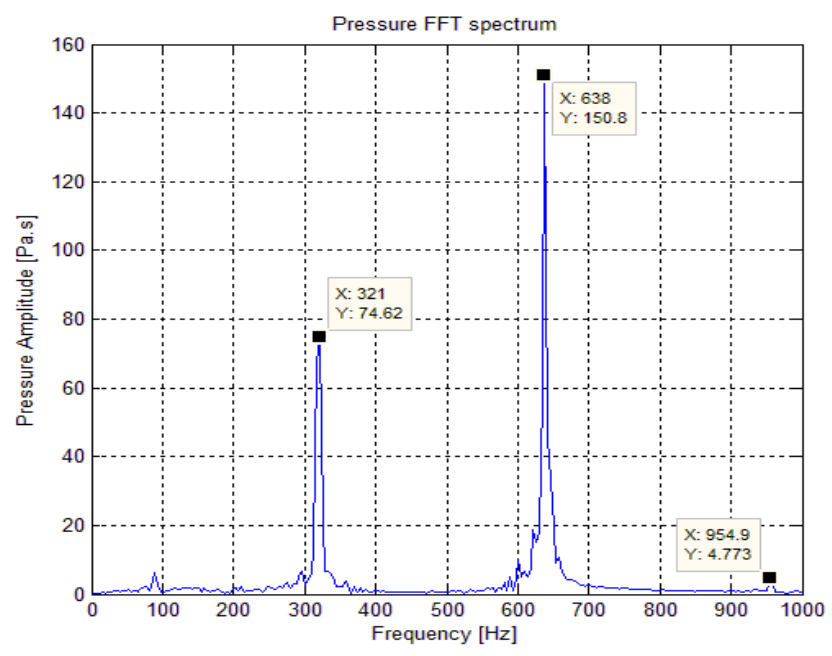

(b)

Fig 8. Calculated pressure for case $40 \mathrm{~kW}$ and $\varphi=0.625$ as a function of time (a) and frequency (b) for a location at $500 \mathrm{~mm}$ above the wedge

Table 5: Predicted eigenfrequencies and pressure amplitude at different locations downstream of the wedge for the case of $60 \mathrm{KW}$

\begin{tabular}{|c|c|c|c|c|c|c|}
\hline & \multicolumn{2}{|c|}{ First peak } & \multicolumn{2}{|c|}{ Second peak } & \multicolumn{2}{|c|}{ Third peak } \\
\hline & $\begin{array}{l}\text { Freq } \\
\text { [HZ] }\end{array}$ & $\begin{array}{l}\text { Amp } \\
{[\mathrm{Pa} . \mathrm{s}]}\end{array}$ & $\begin{array}{l}\text { Freq } \\
{[\mathrm{HZ}]}\end{array}$ & $\begin{array}{l}\text { Amp } \\
{[\text { Pa.s }]}\end{array}$ & $\begin{array}{l}\text { Freq } \\
\text { [HZ] }\end{array}$ & $\begin{array}{l}\text { Amp } \\
{[\text { Pa.s] }}\end{array}$ \\
\hline P4 & \multirow{4}{*}{321.1} & 776 & \multirow{4}{*}{642.3} & 439.9 & \multirow{4}{*}{963.4} & 42.64 \\
\hline $\mathrm{P} 5$ & & 751.5 & & 190.6 & & 108.4 \\
\hline P6 & & 532.4 & & 578.4 & & 55.41 \\
\hline P7 & & 171.9 & & 275.1 & & 79.11 \\
\hline
\end{tabular}

The second peak as it was already discussed is not an acoustic harmonic, and it is identified to be due to the frequency doubling of the first eigenfrequency, which is mainly due to the presence of high non-linearities in the combustion process when a system reaches high amplitude limit cycle oscillations. You can see these nonlinearity effects more clearly in (fig7-a) and (fig8-a). This frequency indeed is driven by the first Eigen mode. The changing pattern in pressure amplitude within the burner in this case represents a traveling wave. the third peak in the pressure data at $\sim 963 \mathrm{~Hz}$ is also observed. The presence of one pressure node along the combustor suggests that this frequency may correspond to $3 / 4$ wave mode.

The simulated time domain and FFT of the pressure field corresponding to a location at $500 \mathrm{~mm}$ above the wedge for the thermal power of $40 \mathrm{KW}$ and $\lambda=1.6$ are plotted in figure 8. The plot indicates clearly limit cycle behaviour in the time domain. But the pressure amplitude in this case is much lower as compared to figure 7 . The pressure spectrum plot shows the fundamental quarter wave mode frequency. The third peak corresponding to the third quarter mode of the setup looks weak with very small pressure amplitude. As it can be observed in this case also the main instability occurs at the second peak $(\sim 638 \mathrm{~Hz})$.

Acoustic natural frequencies are obtained from the spectrum of the different pressure transducers located in the combustion chamber for the case of $40 \mathrm{KW}$ are presented in table 6 and 7 respectively for upstream and downstream of the wedge (see figure 4). As it can be seen in the investigated frequency range, three modes are observed. For the second and third modes a minor difference in the frequency between the cases of $40 \mathrm{KW}$ and $60 \mathrm{KW}$ is observed. The amplitude of the peaks is also lower as compared to the case of $60 \mathrm{KW}$. The instabilities are mainly placed in the vicinity of the first and the second peak. The third peak looks weak with a very small pressure amplitude, and this peak is not visible in the location of $\mathrm{P} 3$ because of its mode shape.

Table 6: Predicted eigenfrequencies and pressure amplitude at different locations upstream of the wedge for case of $40 \mathrm{KW}$

\begin{tabular}{|c|c|c|c|c|c|c|}
\hline & \multicolumn{2}{|c|}{ First peak } & \multicolumn{2}{|c|}{ Second peak } & \multicolumn{2}{|c|}{ Third peak } \\
\hline & $\begin{array}{l}\text { Freq } \\
\text { [HZ] }\end{array}$ & $\begin{array}{l}\text { Amp } \\
{[\mathrm{Pa} . \mathrm{s}]}\end{array}$ & $\begin{array}{l}\text { Freq } \\
{[\mathrm{HZ}]}\end{array}$ & $\begin{array}{l}\text { Amp } \\
{[\mathrm{Pa} . \mathrm{s}]}\end{array}$ & $\begin{array}{l}\text { Freq } \\
{[\mathrm{HZ}]}\end{array}$ & $\begin{array}{l}\text { Amp } \\
{[\mathrm{Pa} . \mathrm{s}]}\end{array}$ \\
\hline P1 & \multirow{3}{*}{321} & 332 & \multirow{3}{*}{638} & 123.7 & \multirow{3}{*}{959} & 4.451 \\
\hline $\mathrm{P} 2$ & & 231.3 & & 23.65 & & 9.112 \\
\hline P3 & & 76.95 & & 139 & & --- \\
\hline
\end{tabular}

Table 7: Predicted eigenfrequencies and pressure amplitude at different locations downstream of the wedge for case of $40 \mathrm{KW}$

\begin{tabular}{|c|c|c|c|c|c|c|}
\hline & \multicolumn{2}{|c|}{ First peak } & \multicolumn{2}{|c|}{ Second peak } & \multicolumn{2}{|c|}{ Third peak } \\
\hline & $\begin{array}{l}\text { Freq } \\
{[\mathrm{HZ}]}\end{array}$ & $\begin{array}{l}\text { Amp } \\
{[\text { Pa.s] }}\end{array}$ & $\begin{array}{l}\text { Freq } \\
{[\mathrm{HZ}]}\end{array}$ & $\begin{array}{l}\text { Amp } \\
{[\text { Pa.s] }}\end{array}$ & $\begin{array}{l}\text { Freq } \\
{[\mathrm{HZ}]}\end{array}$ & $\begin{array}{l}\text { Amp } \\
{[\text { Pa.s] }}\end{array}$ \\
\hline $\mathrm{P} 4$ & \multirow{4}{*}{321} & 117.5 & \multirow{4}{*}{638} & 137.6 & \multirow{4}{*}{955} & 3.952 \\
\hline P5 & & 109.9 & & 28 & & 9.936 \\
\hline $\mathrm{P} 6$ & & 74.62 & & 150.8 & & 4.773 \\
\hline P7 & & 23.87 & & 75.99 & & 7.514 \\
\hline
\end{tabular}




\section{RESULTS/STRUCTURAL BEHAVIOR}

Figure 9 and 10 show the calculated wall displacement at different monitor points according to figure 3. The time domain indicates a wall displacement in the range of $\left(10^{-9}-10^{-8}\right.$ ) meter from the static position. One can see that the peaks present in the pressure spectrum are approximately reproduced in the wall displacement results.

However the results on the right hand side show a few significant peaks in the lower frequency domain, which can be attributed to the fact that the liner has dynamics, resonant eigen frequencies, at lower frequencies as compared to that of the fluid domain. The oscillations occurring are fed by energy derived from the acoustic fluid oscillation but vibrate at the structural eigenfrequencies. In the frequency spectrum (see fig. 9) the dominant vibration frequency is $\sim 317 \mathrm{HZ}$, while according to fig. 10 it can be seen that depending on the location of the monitor point more instability in the displacement can be found in the lower frequency domain. The interesting thing to observe is that the displacement is increasing with distance away from the wedge, which is expected due to the clamped structural condition at the wedge location.
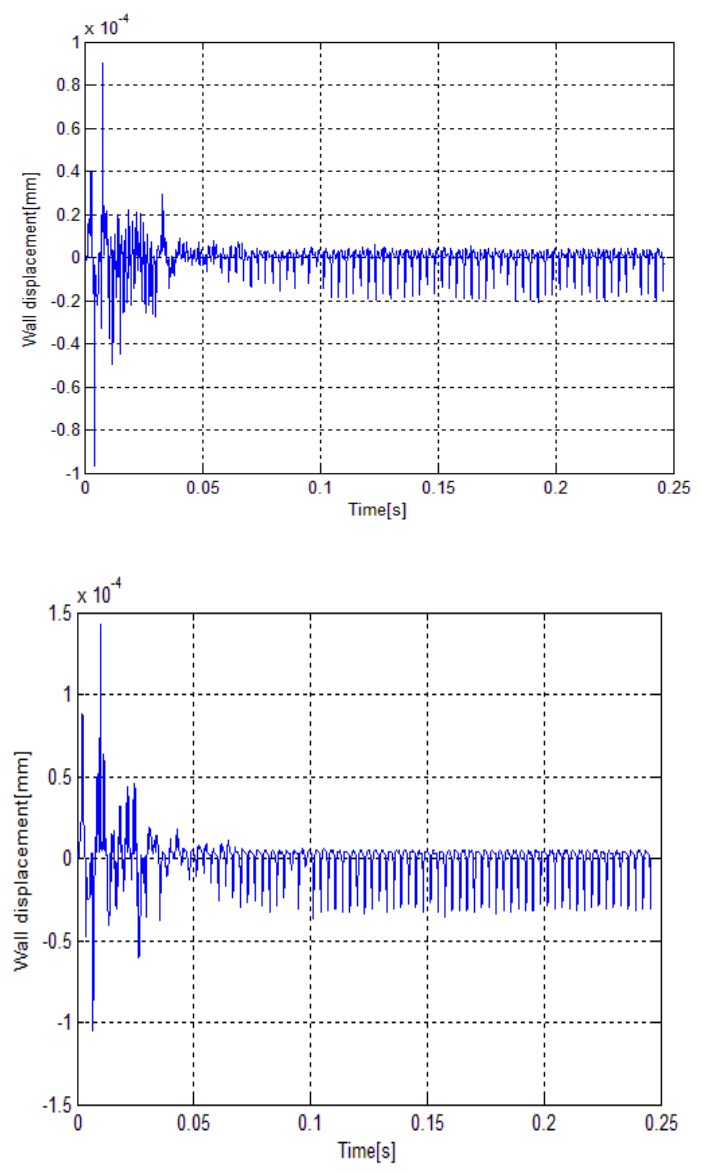

(b)
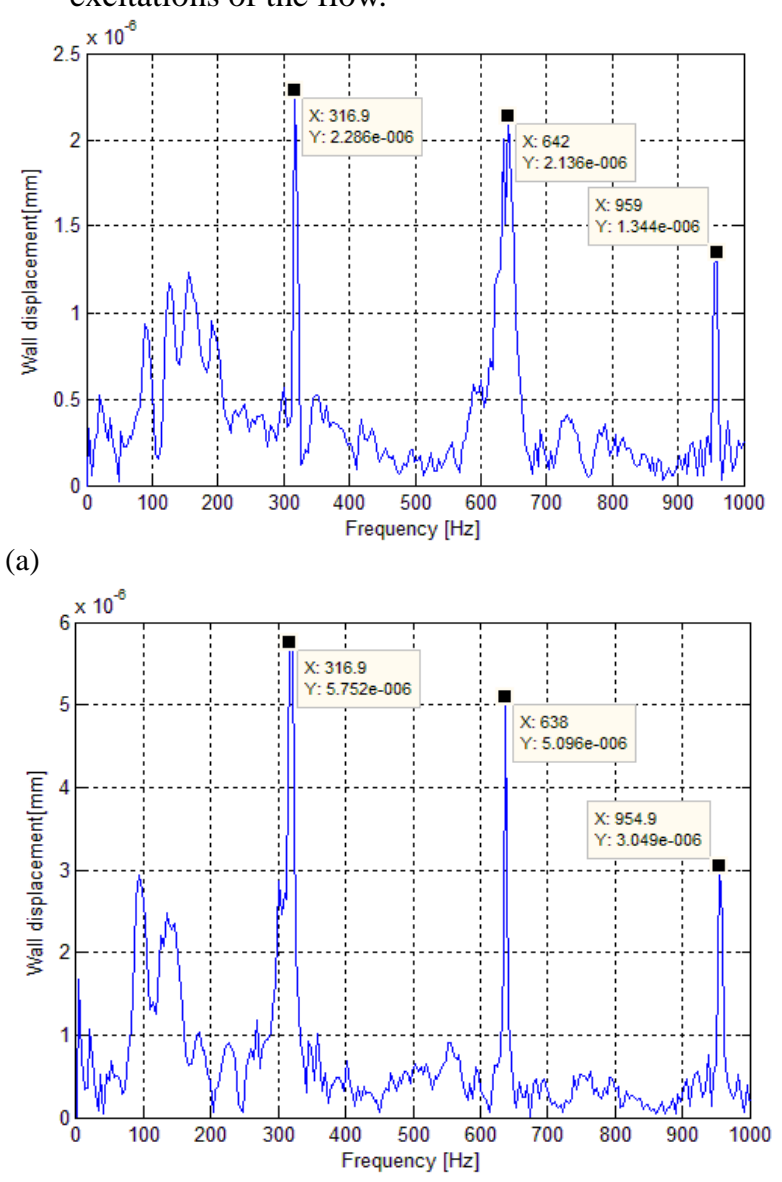

a)

- The obtained displacement history shows that the maximal displacement exhibited by the structure lies in the range of $10^{-9}$ meter. Indeed, such displacements are extremely small. And Indeed the turbulent flow usually cannot be affected by such small deformation. However, these displacements suggest that the structure can possibly act as a source for acoustic excitations of the flow.

equency (right) at (a)100 mm (b) $300 \mathrm{~mm}$ downstream of the wedge for the case of $\mathbf{4 0 k W}$ and $\boldsymbol{\varphi}=\mathbf{0 . 6 2 5}$ on the wall number 

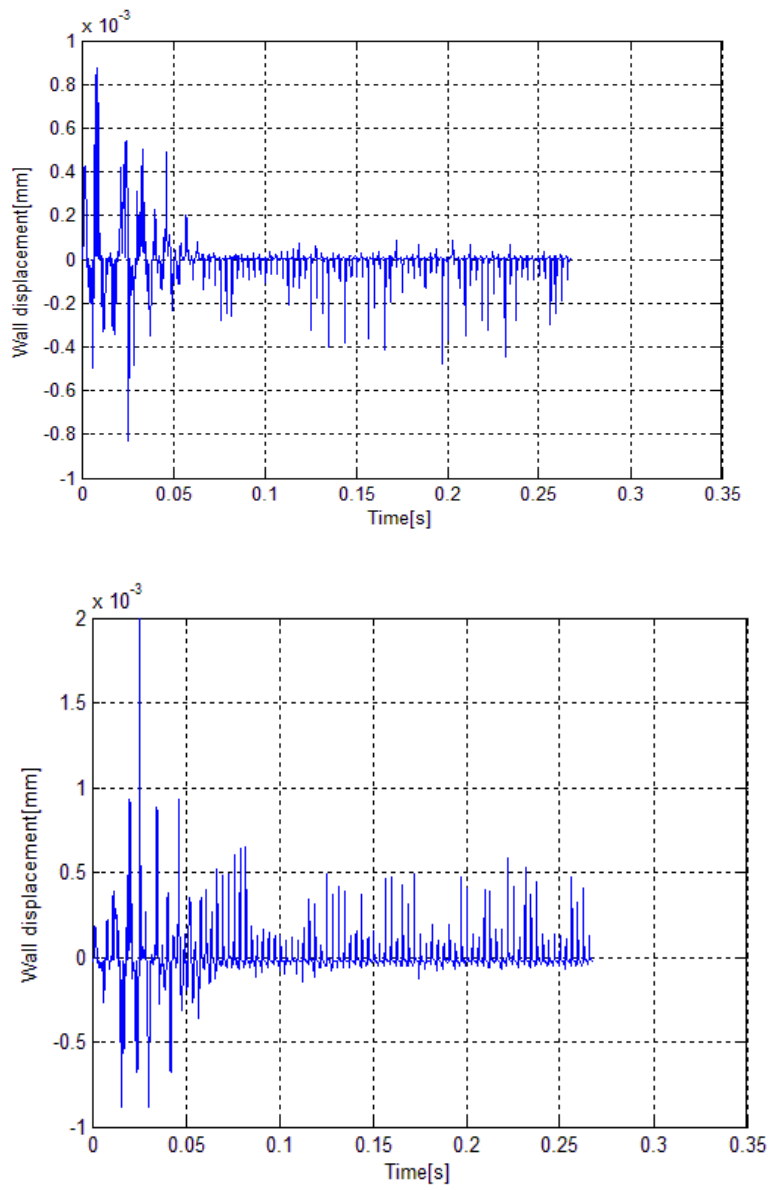

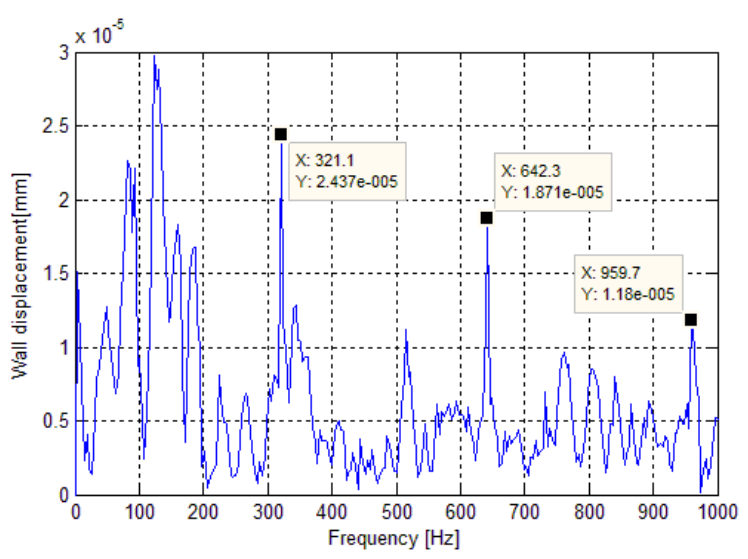

(a)

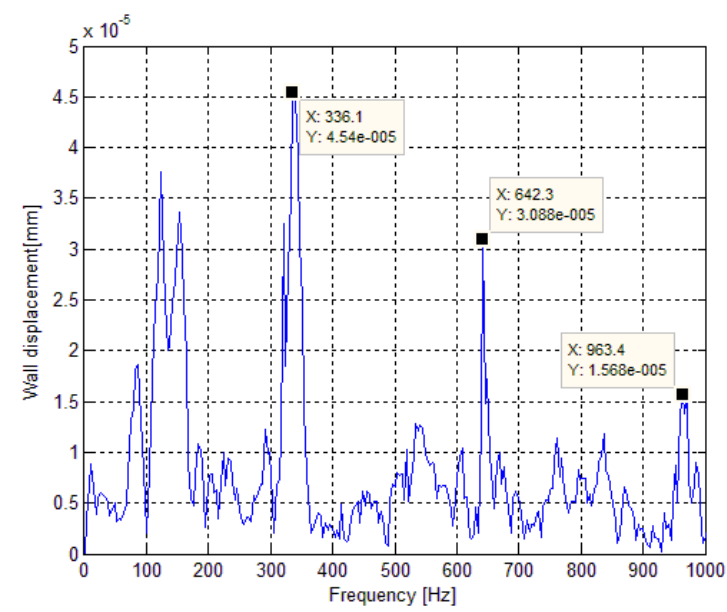

(b)

Fig. 10. wall displacement signal as a function of time (left) and frequency (right) at (a)200 mm (b) $400 \mathrm{~mm}$ downstream of the wedge for the case of $60 \mathrm{~kW}$ and $\boldsymbol{\varphi}=\mathbf{0 . 6 2 5}$ on the wall number 2

\section{ACKNOWLEDGMENTS}

The authors would like to acknowledge the funding of this research by the EC in the Marie Curie Actions Networks for Initial Training, under call FP7-PEOPLE-2007-1-1-ITN, Project LIMOUSINE with project number 214905.

\section{REFERENCES}

[1] Sanjay M. Correa, A Review of NOX formation under gas turbine combustion conditions, Combustion Science and Technology, Volume 87, Issue 1-6, 1993.

[2] A. Can Altunlu, Peter van der Hoogt, André de Boer, Life assessment by fracture mechanics analysis and damage, monitoring technique on combustion liners, ASME Turbo Expo 2011, June 6-10, 2011, Vancouver, Canada.

[3] J.C. Roman Casado, R. Alemela, J. Kok, Combustion dynamics coupled to structural vibrations, In: 17th International Congress on Sound \& Vibration, ICSV 17, July 18-22, 2010, Cairo, Egypt, 2010.
A. Petchenko, V. Bychkov, V. Akkerman, L. Eriksson, Flame-sound interaction in tubes with nonslip walls, Combustion and Flame Volume 149, Issue 4, June 2007, Pages 418-434.

[5] F. Foucher, S. Burnel, C. Mounaïm-Rousselle, M. Boukhalfa, B. Renou, M. Trinite, Flame wall interaction:effect of stretch, Experimental Thermal and Fluid Science, Volume 27, Issue 4, April 2003, Pages 431-437.

[6] R. Huls, Acousto-Elastic Interaction in Combustion Chambers, Enschede : PhD thesis, 2006.

K. Ahn ,Kenneth H. Yu, Effects of Damköhler number on vortex-flame interaction, Combustion and Flame, In Press, Corrected Proof.

[8] A. Pozarlik, Vibro-Acoustical Instabilities Induced by Combustion Dynamics in Gas Turbine Combustors. University of Twente, Enschede, Netherlands: PhD thesis, 2010.

[9] A.K. Pozarlik, J. B.W. kok, Numerical investigation of one- and two way fluid structure interaction in combustion systems, Int. Conf. on Computational Methods for Coupled Problems in Science and 
Engineering, Barcelona, 2007.

[10] R. Alemela, J.C. Roman Casado, S. Kumar and J. Kok, Simulation of limit cycle pressure oscillation with coupled Fluid-Structure interactions in a model combustor, 18th International Congress on Sound \& Vibration, ICSV 18, July 10-14, 2011, Rio De Janeiro, Brazil, 2011.

[11] R. A. Huls, A. X. Sengissen, P. J. M. van der Hoogt, J. B. W. Kok, T. Poinsot, and A. de Boer, Vibration prediction in combustion chambers by coupling finite elements and large eddy simulations, Journal of Sound and Vibration 304, 224 -229, 2007.

[12] J. Rayleigh, The explanation of certain acoustic phenomena, Nature, 18, 319-321, 1878.

[13] P. Rijke, On the vibration of the air in a tube open at both ends, Philosophical Magazine, vol. 17, 419-422, 1859.

[14] F.Menter, M Kuntz., R. Bender, A scale-adaptive simulation model for turbulent flow predictions, AIAA Paper 0767, 2003.

[15] ANSYS workbench user manual. s.1.: ANSYS , 2010.

[16] www.kxcad.net Home > CAE Index > ANSYS Index $>$ Release 11.0 Documentation for ANSYS.

\section{APPENDIX}

\section{MATHEMATICAL FORMULATION :}

\section{GOVERNING EQUATIONS FOR NEWTONIAN COMPRESSIBLE FLIUD}

The Favre average mass, momentum and energy

conservation can be written as following,

- Conservation of mass

$\frac{\partial \bar{\rho}}{\partial t}+\frac{\partial\left(\bar{\rho} \widetilde{u}_{i}\right)}{\partial x_{i}}=0$

- Momentum

$\frac{\partial\left(\bar{\rho} \widetilde{u}_{i}\right)}{\partial t}+\frac{\partial\left(\bar{\rho} \widetilde{u}_{i} \widetilde{u}_{j}\right)}{\partial x_{i}}=-\frac{\partial \bar{p}}{\partial x_{i}}+\frac{\partial}{\partial x_{i}}\left(\overline{\tau_{i j}}-\overline{\rho u_{l}^{\prime \prime} u_{\jmath}^{\prime \prime}}\right)$

$\tau$ is the stress tensor which is related to the strain rate by:

$\overline{\tau_{i j}}=\widetilde{\tau_{l j}}+\overline{\tau_{i j}{ }^{\prime \prime}}$

- energy equation

$$
\begin{gathered}
\frac{\partial\left(\bar{\rho} \widetilde{e_{0}}\right)}{\partial t}+\frac{\partial}{\partial x_{j}}\left(\bar{\rho} \tilde{u}_{i}{\widetilde{e_{0}}}+\tilde{u}_{j} \bar{p}+\overline{u_{j}{ }^{\prime p} p}+\overline{\rho u_{j}{ }^{\prime \prime} e_{0}{ }^{\prime}}+\overline{q_{j}}-\overline{u_{i} \tau_{i j}}\right) \\
=0
\end{gathered}
$$

Which $\widetilde{e_{0}}$ is given by:

$\widetilde{e_{0}} \equiv \widetilde{e}+\tilde{u}_{k} \tilde{u}_{k} / 2+k$
Where the turbulent energy, $\mathrm{k}$, is defined by:

$k=\frac{u_{k}^{\prime \prime} u_{k}^{\prime \prime}}{2}$

The unclosed terms contain products of fluctuating values $\overline{\text { l.e. } \rho u_{\imath}^{\prime \prime} u_{\jmath}^{\prime \prime}}$, which need to be modeled.

\section{FINITE ELEMENT APPROXIMATIONS FOR STRUCTURAL ANALYSIS}

The FEM formulation is derived from an assumption made on element displacement $\mathbf{u}$. A point inside an element is selected where $\mathbf{u}$ describes the displacement at the point, $\mathbf{N}$ contains the position of the point and $\mathbf{d}$ is a vector containing displacement on the nodal points. In general form with $n$ number of nodes in an element $\mathrm{e}$ :

$\boldsymbol{u}=\sum_{k=1}^{n} N_{k}^{\beta} d_{k}^{\beta}=\left[\boldsymbol{N}_{1}^{\beta}, \boldsymbol{N}_{2}^{\beta}, \ldots\right]\left\{\begin{array}{c}\boldsymbol{d}_{1}^{\beta} \\ \boldsymbol{d}_{2}^{\beta} \\ \cdot \\ \cdot\end{array}\right\}=\boldsymbol{N} \boldsymbol{d}$

Where $\mathrm{k}=1,2, \ldots, \mathrm{n}$ and $\beta=1,2,3$ due to 3 dimensions.

So the velocity $\mathbf{v}$ at any chosen point can easily be described as:

$\boldsymbol{V}=\sum_{k=1}^{n} N_{k}^{\beta} w_{k}^{\beta}=\left[\boldsymbol{N}_{1}^{\beta}, \boldsymbol{N}_{2}^{\beta}, \ldots\right]\left\{\begin{array}{c}\boldsymbol{w}_{1}^{\beta} \\ \boldsymbol{w}_{2}^{\beta} \\ \cdot \\ \cdot\end{array}\right\}=\boldsymbol{N} \boldsymbol{w}$

where $\mathbf{w}$ is nodal velocity.

Due to large displacements it is necessary to describe equilibrium and geometrical changes in details. In a deformed body the internal forces are mainly characterized by Cauchy stresses. Differential equation for equilibrium expressed in Cauchy stresses $\sigma$ is described as:

$\operatorname{div}(\sigma)+b=\rho_{t} \dot{v}$

Where $\mathrm{b}$ is the body force acting on the solid, $\rho_{t}$ is the mass density in deformed geometry, and $\dot{v}$ is the acceleration.

The principle of virtual work for this problem is:

$$
\begin{gathered}
\int_{V_{0}} \sigma: \operatorname{grad}(\tilde{V}) J d V_{0}+\int_{V_{0}} b \cdot \tilde{V} J d V_{0}+\int_{A_{0}} t \cdot \tilde{V} J^{*} d A_{0} \\
=\int_{V_{0}} \rho \dot{v} \cdot \tilde{V} J d V_{0}
\end{gathered}
$$

Changes of the reference volume $\left(\mathrm{V}_{0}\right)$ to the deformed volume $(\mathrm{V})$ is described by

$J=d V / d V_{0}$

Where $\mathbf{J}$ is the Jacobian determinant. Changes in area element is described by:

$J^{*}=d A / d A_{0}$

\section{SCALE ADAPTIVE SIMULATION (SAS-SST MODEL)}

The Scale-Adaptive Simulation (SAS) is an advanced URANS model [14], which allows better resolution of the turbulent spectrum in unstable flow conditions. One of the more interesting features of the SAS approach is that for 
unstable flows, the model changes smoothly from a LES model through various stages of eddy-resolution back to a steady RANS model, based on the specified time step. The starting point of the transformation to the SST model is the $k-v_{t}$ formulation as given by Menter et al. [14]. The following equations have been derived there for the variables $\mathrm{k}$ and $\varphi=\mathrm{k}^{1 / 2} \mathrm{~L}$ :

$\frac{\partial \rho k}{\partial t}+\frac{\partial U_{j} \rho k}{\partial x_{j}}=P_{K}-c_{\mu}^{\frac{3}{4}} \rho \frac{k^{2}}{\Phi}+\frac{\partial}{\partial x}\left[\frac{\mu_{t}}{\sigma_{k}} \frac{\partial k}{\partial y}\right]$

$\frac{\partial \rho \Phi}{\partial t}+\frac{\partial U_{j} \rho \Phi}{\partial x_{j}}=\zeta_{1} \frac{\phi}{k} P_{K}-\zeta_{2} \mu_{t} S\left|U^{\prime \prime}\right| \frac{\Phi^{2}}{k^{3 / 2}}-\zeta_{3} \rho k$

$$
+\frac{\partial}{\partial y}\left[\frac{\mu_{t}}{\sigma_{\phi}} \frac{\partial \Phi}{\partial y}\right]
$$

$v_{t}=c_{\mu}^{1 / 4} \Phi$

with

$$
\left|U^{\prime \prime}\right|=\sqrt{\frac{\partial^{2} U_{i}}{\partial x_{j}^{2}} \frac{\partial^{2} U_{i}}{\partial x_{j}^{2}}}
$$

Where $\mathrm{S}$ is the absolute value of strain rate, $\mathrm{P}_{\mathrm{k}}$ is the production rate of turbulent kinetic energy and $c_{\mu}=0.09, k=0.41$.

This SAS-relevant term in the equation for $\Phi$ is the term with second derivative $\left|U^{\prime \prime}\right|$ as a result the length scale predicted by the above model is largely proportional to the von Karman length scale:

$$
L_{v K}=\mathrm{K}\left|\frac{\frac{\partial U}{\partial y}}{\frac{\partial^{2} U}{\partial y^{2}}}\right|
$$

\section{BURNING VELOCITY MODEL}

In premixed and partially premixed flames, the flamelets have a discontinuity between the burnt and the un-burnt regions; therefore the model for premixed or partially premixed combustion can be split into two independent parts [15]:

- Model for the progress of the global reaction: Burning Velocity Model (BVM), also called Turbulent Flame Closure (TFC)

- Model for the composition of the reacted and nonreacted fractions of the fluid: Laminar Flamelet with PDF

In this model a scalar (Reaction Progress) subdivides the flow field in two different areas, the burnt and the un-burnt mixture. Burnt regions are treated similar to a diffusion flame whereas the un-burnt region is represented by the cold mixture. The mass fractions in the non-reacted fraction of the fluid, $Y_{i, f r e s h}$, are obtained by linear blending of fuel and oxidiser compositions. The species mass fractions in the burned fraction of the fluid, $\mathrm{Y}_{\mathrm{i}, \text { burned }}$, are computed by applying the flamelet model.

In turbulent flow, a bimodal distribution of reaction progress variable is assumed. At any given time and position in space the fluid is considered to be either fresh materials or fully reacted. This assumption is justified if the chemical reaction is fast compared to the integral turbulent time scales of the flow. Then, the averaged reaction progress variable, $\tilde{c}$, is the probability for the instantaneous state of the fluid being reacted. The mean species composition of the fluid is computed according to:

$$
\begin{aligned}
& \widetilde{Y}_{1}=(1-\tilde{\mathrm{c}}) \widetilde{\mathrm{Y}}_{i, \text { fresh }}+\tilde{\mathrm{c}} \widetilde{\mathrm{Y}}_{\mathrm{i}, \text { burned }} \\
& \text { and } \\
& \widetilde{\mathrm{F}}=\tilde{\mathrm{Z}} \cdot(1-\tilde{\mathrm{c}})
\end{aligned}
$$

are mixture fraction, respectively. The weighted reaction progress variable is computed by solving a transport equation:

$$
\begin{aligned}
\frac{\partial(\bar{\rho} \tilde{\mathrm{F}})}{\partial \mathrm{t}}+\frac{\partial\left(\bar{\rho} \tilde{\mathrm{u}_{\mathrm{j}}} \tilde{\mathrm{F}}\right)}{\partial \mathrm{x}_{\mathrm{j}}} & =\frac{\partial}{\partial \mathrm{x}_{\mathrm{j}}}\left[\left(\overline{\rho \mathrm{D}}+\frac{\mu_{\mathrm{t}}}{\sigma_{\mathrm{F}}}\right) \frac{\partial \tilde{\mathrm{F}}}{\partial \mathrm{x}_{\mathrm{j}}}\right] \\
& +2\left(\overline{\rho \mathrm{D}}+\frac{\mu_{\mathrm{t}}}{\sigma_{\mathrm{F}}}\right)\left(\frac{\partial \tilde{\mathrm{Z}}}{\partial \mathrm{x}_{\mathrm{j}}} \cdot \frac{\partial \tilde{\mathrm{c}}}{\partial \mathrm{x}_{\mathrm{j}}}\right)-\tilde{\mathrm{Z}} \overline{\omega_{\mathrm{c}}}
\end{aligned}
$$

The default value of the turbulent Schmidt number for the weighted reaction progress variable is $\sigma_{\mathrm{F}}=0.9$.

The burning velocity model (BVM) is used to close the combustion source term for reaction progress.

$$
\begin{aligned}
& \bar{\omega}_{\mathrm{c}}=\overline{\mathrm{S}}_{\mathrm{c}}-\frac{\partial}{\partial \mathrm{x}_{\mathrm{j}}}\left((\overline{\rho \mathrm{D}}) \frac{\partial \tilde{\mathrm{c}}}{\partial \mathrm{x}_{\mathrm{J}}}\right) \\
& \overline{\mathrm{S}}_{\mathrm{c}}=\bar{\rho}_{\mathrm{u}} \mathrm{S}_{\mathrm{T}}|\nabla \tilde{\mathrm{c}}|
\end{aligned}
$$

Where $\bar{\rho}_{\mathrm{u}}$ is the density of the unburnt mixture. The diffusive exchange of species and energy, which makes the flame proceed in space, is already accounted for by the source $\operatorname{term} \overline{\mathrm{S}}_{\mathrm{c}}$. 